\title{
ESTIMASI BIOMASSA DAN KARBON TEGAKAN DIPTEROCARPA PADA EKOSISTEM HUTAN PRIMER DAN LOA (LOG OVER AREA) DI PT. SARI BUMI KUSUMA (SBK) KALIMANTAN TENGAH
}

\author{
Sabaria Niapele \\ Staf Pengajar FAPERTA UMMU-Ternate, $e$-mail: -
}

\begin{abstract}
ABSTRAK
Biomassa pohon dihutan merupakan tempat penyimpan cadangan karbon terbesar terdapat pada batang, cabang, ranting, daun dan akar. Selain untuk menyimpan cadangan karbon, pohon juga meyerap karbon dari atmosfer dalam bentuk karbondioksida $\left(\mathrm{CO}_{2}\right)$ melalui proses fotosintesis sehingga gas $\mathrm{CO}_{2}$ diatmosfer dapat berkurang. Oleh karena itu perlu adanya pengukuran biomassa dan karbon pohon di hutan untuk mengestimasi seberapa besarkah pohon dapat menyimpan biomassa dan karbon serta mampu menyerap $\mathrm{CO}_{2}$ dari atmosfer melalui pendekatan allometrik. Penelitian dilakukan di areal PT. SBK Kalimantan Tengah, Laboratorium THH Fakultas Kehutanan UGM dan Laboratorium BPTP Yogyakarta dengan tujuan membuat persamaan allometrik untuk menentukan potensi biomassa, potensi karbon, dan potensi penyerapan $\mathrm{CO}_{2}$ di PT. SBK. Pohon dipilih berdasarkan kriteria variasi umur dan dbh. Kandungan biomassa diketahui melalui metode pengukuran secara destructive, selanjutnya dibuat persamaan allometrik biomassa dan karbon untuk mengetahui kandungan potensi biomassa dan karbon. Hasil penelitian menunjukan bahwa variabel dbh dapat digunakan untuk menaksir biomassa total pohon melalui model power dengan nilai koefisien determinasi sebesar 99,2\%. Jumlah potensi biomassa total pohon yang tersimpan pada TPTI (tahun tanam 1995-2010) adalah 311,67 ton/ha. Jumlah potensi karbon pohon yang tersimpan pada TPTI (tahun tanam 1995-2010) adalah 143,31 ton/ha. Sedangkan potensi penyerapan $\mathrm{CO}_{2}$ pada TPTI (tahun tanam 1995-2010) adalah 525,96 ton/ha.
\end{abstract}

Kata Kunci: Biomassa, Karbon, PT. SBK, Allometrik

\section{PENDAHULUAN}

Biomassa pohon di hutan tropis yang didominasi oleh jenis-jenis dipterocarpa merupakan tempat penyimpan cadangan karbon terbesar yang terdapat pada batang, cabang, ranting, daun dan akar. Selain untuk menyimpan cadangan karbon, pohon juga dapat meyerap karbon dari atmosfer dalam bentuk karbondioksida $\left(\mathrm{CO}_{2}\right)$ melalui proses fotosintesis sehingga gas $\mathrm{CO}_{2}$ di atmosfer dapat berkurang. Sementara meningkatnya kerusakan hutan berupa perubahan tata guna lahan, kebakaran hutan, deforestasi, degradasi, pemanfaatan bahan bakar fosil, industri telah menyebabkan tingginya tingkat emisi karbon di atmosfer. Salah satu jawaban untuk dapat menurunkan tingkat emisi gas rumah kaca di atmosfer yaitu hutan. Hutan mempunyai peranan yang sangat penting dalam menyerap $\mathrm{CO}_{2}$ dan diharapkan dapat menurunkan emisi gas rumah kaca di atmosfer. Oleh karena itu perlu adanya pengukuran biomassa dan karbon pohon di hutan untuk mengestimasi seberapa besarkah pohon dapat menyimpan biomassa dan karbon serta mampu menyerap $\mathrm{CO}_{2}$ dari atmosfer. 
Laurance (1999) menyatakan bahwa hutan tropis direkomendasikan di seluruh dunia karena biodiversitasnya yang tinggi, perannya dalam mencegah banjir, konservasi tanah, penyimpan cadangan karbon, dan pengaruhnya terhadap iklim. PT SBK di Kalimantan Tengah merupakan salah satu kawasan hutan hujan tropis di Indonesia yang mendapat Izin Usaha Pemanfaatan Hasil Hutan Kayu (IUPHHK) yang termasuk dalam 6 IUPHHK model yang bertugas untuk menguji Silvikultur Intensif (SILIN) dalam skla unit manajemen dan 3 diantaranya termasuk PT SBK dijadikan contoh model untuk melaksanakan SILIN. PT SBK belum pernah melakukan penelitian sebelumnya tentang pengukuran biomassa dan karbon pohon sehingga perlu adanya penelitian ini untuk mendapatkan informasi tentang biomassa dan karbon yang tersedia di PT SBK

Berdasarkan uraian di atas maka dalam penelitian ini dirumuskan permasalahan yaitu: Bagaimana membuat model persamaan allometrik biomassa untuk dapat menentukan karbon yang tersimpan pada hutan hujan tropis di areal hutan untuk dapat mengetahui berapa besar potensi karbon yang terdapat pada areal PT SBK.

Oleh karena itu perlu dilakukan penelitian yang bertujuan untuk (1). Membuat persamaan allometrik biomassa dan karbon (2). Mengetahui potensi kandungan biomassa. (3). Mengetahui potensi kandungan karbon yang tersimpan (4). Mengetahui potensi serapan $\mathrm{CO}_{2}$.

\section{METODE PENELITIAN}

\subsection{Waktu dan Lokasi}

Penelitian ini dilaksanakan selama 10 bulan, yakni bulan Juli sampai April 2010. Penelitian ini dilaksanakan di areal PT SBK dan di Laboratorium Teknologi Hasil Hutan, Fakultas Kehutanan UGM dan Balai Pengkajian Teknologi Pertanian (BPTP) Yogyakarta.

\subsection{Obyek Penelitian}

Obyek penelitian adalah pohon-pohon dari berbagai variasi ukuran diameter ( $\mathrm{dbh}$ ) yang tumbuh pada ekosistem hutan primer dan hutan bekas tebangan (Log Over Area/LOA) .
Penelitian difokuskan pada bagian organ pohon yang berada di atas tanah (batang, cabang, ranting, dan daun) serta di bawah tanah (akar).

\subsubsection{Pemilihan Pohon Sampel}

Pemilihan pohon sampel yang dijadikan objek untuk penelitian kandungan biomassa dan kandungan karbon dilakukan secara purposive setelah observasi lapangan. Pohon yang dipilih berdasarkan kriteria variasi umur dan dbh pada ekosistem jalur dan variasi diameter pada pada hutan primer dan LOA. Pemilihan sampel pohon juga dilakukan atas pertimbangan kondisi lapangan. Pohon yang dijadikan pohon sampel yaitu yang mewakili tegakan yang memiliki diameter rata-rata dan yang sehat. Dalam penelitian ini jumlah sampel yang diambil sebanyak 17 pohon pada gabungan ekosistem hutan primer dan LOA.

\subsubsection{Perhitungan Biomassa}

1. Biomassa Batang

Untuk mengetahui biomassa batang, hal pertama yang harus dilakukan adalah menghitung volume batang dan mengukur kerapatan jenis kayu (wood density).

$$
\text { Kerapatan Kayu }=\frac{\text { Berat Kering Disc }}{\text { Volume Disc }}
$$

\section{Sehingga:}

Biomassa batang $($ Stem Weigh/W $)=$ Kerapatan kayu X volume batang.
2. Biomassa Cabang/Dahan/Ranting (Branch weight/ $\mathbf{W}_{b}$ )

$$
\text { Biomassa Cabang }\left(W_{b}\right)=\frac{\text { Berat Kering sampel cabang }}{\text { Berta basah sampel cabang }}
$$

\section{Biomassa Daun (leaf weight/Wl)}

Biomassa daun (leaf weight $/$ il) $=\frac{\text { Berat kering sampel }}{\text { Berat basah sampel daun }}$ berat basah total Biomassa akar (root weiht $\left./ W_{t}\right)=\frac{\text { Berat Kering sampel akar }}{\text { Berat basah sampel akar }} \times$ berat basah total

\section{Biomassa Total Pohon (Total Weight/Wt) \\ Total Biomassa pohon meliputi}

biomassa batang, cabang, daun dan akar.

Biomassa Total $\left(W_{t}\right)=W_{s}+W_{b}+W_{l}+W_{r}$ 

2.2.3. Allometrik

$$
\mathbf{Y}=\mathbf{a x} \mathbf{x}^{\mathbf{b}}
$$

Data-data yang ada tentang dbh, tinggi total pohon, volume, biomassa dan kandungan karbon dicari hubungannya. Untuk menghubungkan satu data dengan data yang lainnnya digunakan metode regresi. Secara umum metode regresi mempunyai bentuk sebagai berikut (Supranto, 2009).

Keterangan:

$$
\begin{aligned}
\mathrm{Y}= & \text { Variabel bergantung (berupa } \\
& \text { volume, biomassa, karbon dan lain- } \\
& \text { lain) } \\
\mathrm{a}, \mathrm{b}= & \text { Konstanta } \\
\mathrm{X}= & \text { Variabel bebas (berupa diameter) }
\end{aligned}
$$

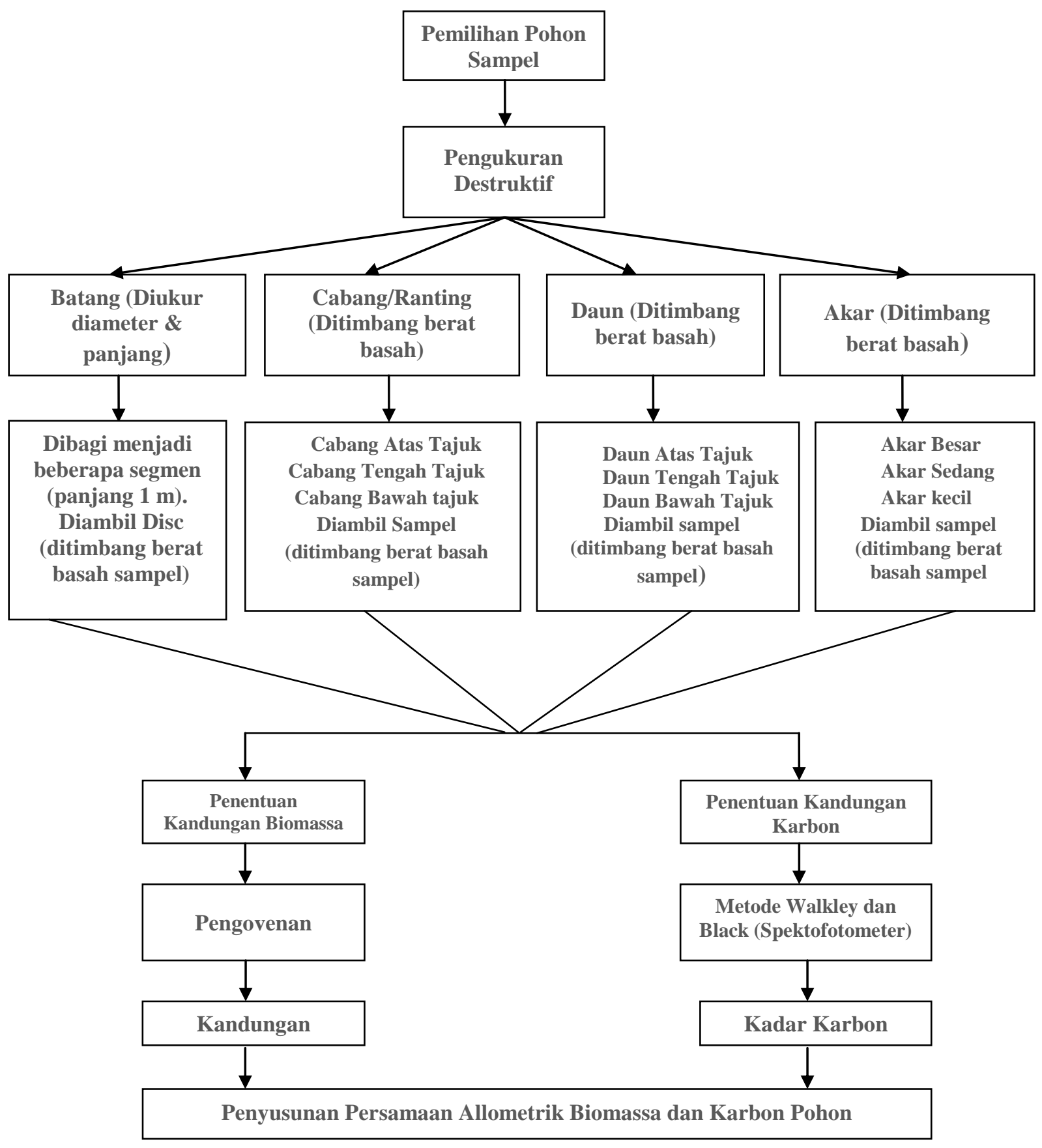

Gambar 1. Prosedur Penelitian di Lapangan

\subsubsection{Perhitungan Kadar Karbon Total}

Besarnya kandungan karbon yang terdapat di permukaan dan dalam tanah yaitu dengan mengalikan biomassa masing-masing organ tanaman dengan presentase berat 


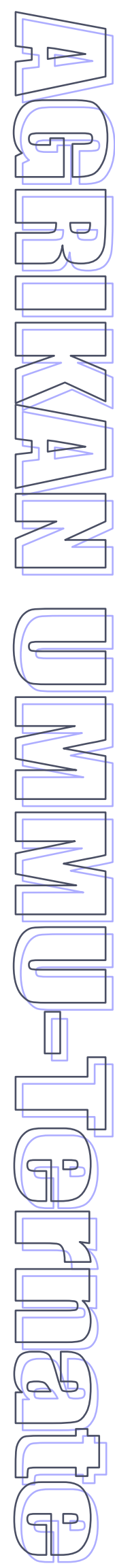

kandungan karbon total hasil perhitungan analisis kimia dengan rumus sebagai berikut:

$$
\mathrm{C}_{\mathrm{t}}=\mathrm{W}_{\mathrm{t}} \mathrm{X} \% \text { Kadar karbon }(\% \mathrm{C})
$$

Keterangan:

$$
\begin{array}{rlrl}
\mathrm{C}_{\mathrm{t}} & = & \text { Berat Kandungan Karbon }(\mathrm{g}, \mathrm{kg}) \\
\mathrm{W}_{\mathrm{t}}= & \text { Berat Biomassa }(\mathrm{g}, \mathrm{kg}) \\
\%(\mathrm{C})= & \text { Kandungan Karbon Total } \\
& (\mathrm{C} \text { Total \%). }
\end{array}
$$

2.2.5. Potensi Penyerapan Karbondioksida $\left(\mathrm{CO}_{2}\right)$

$$
\mathrm{WCO}_{2}=\mathrm{W}_{\mathrm{tc}} \times 3,67
$$

Keterangan:

$$
\begin{aligned}
\mathrm{WCO}_{2}= & \begin{array}{l}
\text { Banyaknya } \\
\text { diserap (Ton } / \text { ha) }
\end{array} \\
\mathrm{CO}_{\mathrm{tc}}= & \begin{array}{l}
\text { Berat total ton tegakan tertentu } \\
\text { (ton } / \text { ha) }
\end{array} \\
3,67= & \begin{array}{l}
\text { Angka equivalen } \\
\text { unsur karbon } \mathrm{C} \text { ke } \mathrm{CO}_{2}
\end{array}
\end{aligned}
$$

\section{HASIL DAN PEMBAHASAN}

\subsection{Kandungan Biomassa dan Karbon Pohon}

Biomassa adalah jumlah bahan organik

yang diproduksi oleh organisme per satuan luas pada suatu saat. Pengukuran biomassa pohon dalam penelitian ini dilakukan pada biomassa permukaan tanah (above-ground biomassa) yang terdiri dari batang, cabang, dan daun serta biomassa di bawah permukaan tanah (bellow-ground biomass) meliputi akar pohon. Biomassa seresah, tumbuhan bawah dan tanah tidak diukur dalam penelitian ini. Berdasarkan tujuan yang telah ditetapkan dalam penelitian dan mempertimbangkan kondisi di lapangan, maka 17 sampel

Biomassa pohon yang terkandung di dalam hutan di PT SBK dilakukan dengan dua tahap yaitu (1). Pengkuran berat basah disk dan berat basah total pada organ batang, cabang, daun, dan akar di lapangan, (2) Pengeringan di laboratorium. Khusus untuk biomassa batang diduga degan pendekatan kerapatan kayu dan volume. Hal ini dilakukakan mengigat karena sampel pohon yang ditebang berdiameter besar sehingga tidak memungkinkan untuk di duga dengan pendekatan kadar air.

Pengukuran biomassa pada sampel organ pohon cabang dan daun dibagi atas 3 bagian yaitu bagian bawah, tengah dan atas. Sedangkan pada batang dikelompakan menjadi 2 bagian yaitu batang dari pangkal sampai tbbc (pangkal, dbh dan tbbc) dan dari tbbc ke ujung batang (bawah, tengah dan atas). Untuk akar dibagi menjadi akar besar, sedang dan kecil. Hasil pengukuran sampel pohon di lapangan berupa berat sampel dan berat total sampel tiap organ pohon serta berat kering sampel pohon maka dapat diketahui biomassa yang terkandung dalam organ pohon tersebut. Sedangkan untuk sampel pohon yang tidak dapat ditimbang maka dihitung kerapatan kayu. Dari hasil perhitungan biomassa didapatkan bahwa organ pohon bagian batang adalah bagian pohon yang mempunyai kandungan biomassa tertinggi. .

Berdasarkan hasil penelitian dapat diketahui bahwa biomassa tiap jenis pohon sampel berbeda-beda. Hal ini menurut Daniel dkk (1980), biomassa satu jenis pohon dipengaruhi oleh pertumbuhan jenis tanaman tersebut. Biomassa pohon terdiri dari biomassa batang, biomassa cabang, biomassa daun dan biomassa akar dimana pada penelitian ini biomassa batang mempunyai kandungan biomassa rata-rata sebesar 2387,4 $\mathrm{kg}$ selanjutnnya pada bagian cabang, akar dan daun masing-masing yaitu $(494,82 \mathrm{~kg}),(245,7$ kg) dan (37,5 kg.) Rata-rata biomassa bagian pohon yang mpunyai kandungan biomassa tertinggi terdapat pada batang. Hal ini disebabkan karena batang merupakan bagian berkayu dan tempat penyimpanan cadangan hasil fotosintesis untuk pertumbuhan sedangkan daun walaupun aktifitas fotosintesis terjadi di daun, namun ternyata daun hanya mendapatkan proporsi hasil fotosintesis yang paling terkeci. Distribusi biomassa pada tiap komponen pohon menggambarkan besaran distribusi hasil fotosintesis pohon yang disimpan oleh tanaman. Melalui proses fotosintesis $\mathrm{CO}_{2}$ di udara diserap oleh tanaman, dan dengan bantuan sinar matahari kemudian diubah menjadi karbohidrat untuk selanjutnya didistribusikan ke seluruh tubuh tanaman dan ditimbun dalam bentuk daun, batang, cabang, buah dan bunga (Hairiah dan Rahayu 2007). Secara umum biomassa tiap bagian pohon sampel terbesar diperoleh pada pohon berdiameter yang paling besar dimana pada penelitian ini diameter terbesar pada gabungan ekosistem hutan primer dan LOA yaitu $115 \mathrm{~cm}$ yang menghasilkan biomassa di batang sebesr 
$11.441,7 \mathrm{~kg}$. Hal ini disebabkan biomassa berkaitan erat dengan proses fotosintesis, dimana biomassa bertambah karena tumbuhan menyerap $\mathrm{CO}_{2}$ dari udara dan mengubahnya menjadi senyawa organik dari proses fotosintesis, dan hasil fotosintesis digunakan oleh tumbuhan untuk melakukan pertumbuhan ke arah horisontal dan vertikal. Berikut presentase biomassa organ pohon terhadap biomassa total dalam bentuk diagram dapat dilihat pada Gambar 2.

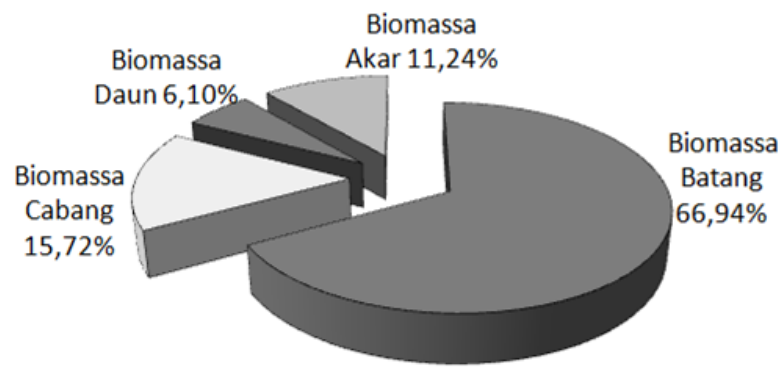

Gambar 2. Diagram Presentase Rata-rata Biomassa Organ Pohon Sampel

Besarnya rata-rata kandungan kadar hutan primer dan LOA maka, kandungan karbon (\%) yang tersimpan pada organ pohon karbon tertinggi terdapat pada bagian batang pada penelitian ini dianalisis menggunakan metode Walkey dan Black (pembacaan dengan spektofotometer). Berdasarkan hasil analisis karbon pada 17 pohon di ekosistem gabungan dan yang terendah terdapat pada bagian daun. Persen kadar karbon pada tiap organ tanaman (batang, cabang, daun dan akar) dapat dilihat pada grafik berikut:

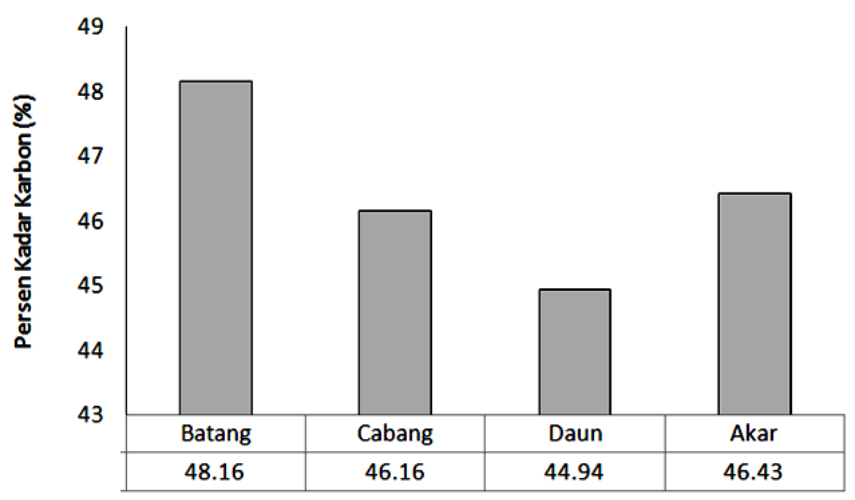

Gambar 3. Grafik Rata-Rata Kandungan Kadar Karbon Tiap Organ Pohon pada Gabungan Ekosistem Hutan Primer dan LOA

Pada grafik di atas dapat dilihat bahwa kandungan persen kadar karbon tiap organ pohon berbeda-beda, hal ini disebabkan karena komponen kimia kayu yang terdapat pada tiap organ pohon berbeda pula. Browning (1967), menyatakan proporsi komponen kimia penyusun kayu sangat bervariasi dari jenis kayu yang satu ke jenis kayu yang lain dan dari pohon ke pohon dalam satu jenis bahkan dari bagian-bagian satu jenis pohon. Hal tersebut dikarenakan komposisi komponen kimia kayu dipengaruhi oleh tipe kayu (normal, tarik atau tekan), bagian kayu (batang, cabang, daun dan akar), lokasi geografis (tempat tumbuh), dan faktor genetik (Pettherson dalam Rowell, 1984). Kandungan karbon organ pohon terhadap karbon total pohon pada hutan tanaman jalur, hutan primer dan LOA digambarkan pada Gambar 4.

\subsection{Persamaan Allometrik}

Hasil analisis hubungan antara biomassa, karbon dan penyerapan $\mathrm{CO}_{2}$ dengan dbh diperoleh persamaan allometrik berbentuk power disajikan pada Tabel 1 dan 2 . 

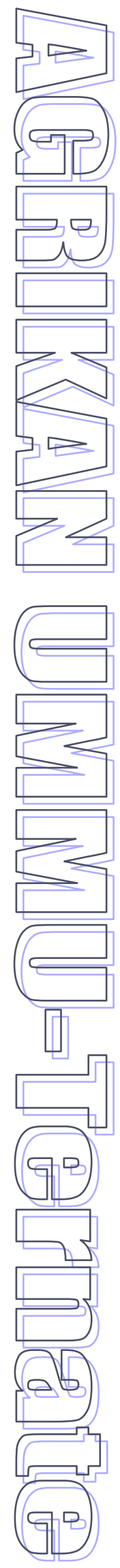

Pengukuran Potensi gas $\mathrm{CO}_{2}$ pada penelitian ini dilakukan dengan menggunakan perbandingan berat massa gas $\mathrm{CO}_{2}$ dengan berat massa atom $\mathrm{C}$. Potensi serapan karbon dalam menyerap gas $\mathrm{CO}_{2}$ dari atmosfer pada TPTI sebesar 525,96 ton/ha terdiri dari batang sebesar 104,45 ton/ha, cabang sebesar 22,4 ton/ha, daun sebesar 2,66 ton/ha dan akar sebesar 13,80 ton/ha

Estimasi terhadap variabel tinggi, volume, biomassa, karbon dan potensi serapan $\mathrm{CO}_{2}$ dari amosfer dapat diduga dengan menggunakan variabel dbh. Persamaan alometrik yang dibuat ini nantinya bisa untuk memudahkan kegiatan pengukuran potensi hutan di PT SBK tanpa harus melakukan penebangan (destruktif sampling method). Persamaan alometrik ini hanya berlaku untuk kondisi hutan di PT SBK dan lokasi-lokasi yang memiliki kondisi karakteristik yang sama dengan SBK.

\section{PENUTUP}

\subsection{Kesimpulan.}

Berdasarkan uraian dalam hasil dan pembahasan maka dapat disimpulkan beberapa kesimpulan sebagai berikut:

1. Persamaan alometrik biomassa pohon yang diperoleh dari sampel pohon pada ekosistem gabungan hutan primer dan LOA yang dapat digunakan untuk menentukan karbon yang tersimpan di PT SBK adalah Biomassa total= 0,162(dbh)2,447. Persamaan alometrik yang telah dibuat ini nantinya bisa untuk memudahkan kegiatan pengukuran potensi karbon di PT SBK tanpa harus melakukan penebangan (destruktif sampling method). Persamaan alometrik ini hanya berlaku untuk kondisi hutan di PT SBK dan lokasi-lokasi yang memiliki kondisi karakteristik yang sama dengan PT SBK. 
2. Besarnya kandungan biomassa yang tersimpan di PT SBK pada TPTI pada tahun tanam 1995 adalah sebesar 317,10 ton/ha

3. Besarnya kandungan karbon yang tersimpan di PT SBK di TPTI pada tahun tanam 1995 adalah 143 ton/ha,

4. Besarnya serapan gas $\mathrm{CO}_{2}$ di PT SBK pada di TPTI pada tahun tanam 1995 adalah 525,96 ton/ha

\subsection{Saran}

Berdasarkan hasil penelitian yang telah dilaksanakan disarankan beberapa hal sebagai berikut:

1. Model pendugaan biomassa dan karbon yang menggunakan persamaan allometrik menghasilkan nilai $\mathbf{R}^{2}$ yang tinggi. Oleh karena itu, disarankan untuk dapat menggunakan persamaan allometrik tersebut karena layak digunakan untuk mengetimasi kandungan karbon di PT SBK.

2. Perlu dibuat suatu sistem pengaturan hasil di PT SBK yang mempertimbangkan serapan karbon disamping menjaga produktifitas produksi kayu.

3. Perlunya penelitian lebih lanjut untuk mengetahui kandungan karbon (seresah, pohon mati, tumbuhan bawah dan tanah) untuk dapat mendapatkan informasi secara lengkap tentang potensi karbon pada kawasan PT SBK.

4. Biomassa pohon di hutan merupakan tempat penyimpan cadangan karbon terbesar. Selain untuk menyimpan cadangan karbon, pohon juga dapat meyerap karbon dari atmosfer melalui proses fotosintesis sehingga gas $\mathrm{CO}_{2} \mathrm{di}$ atmosfer dapat berkurang. Pengukuran biomassa dan karbon pohon di hutan dilakukan untuk mengestimasi biomassa dan karbon serta penyerapan $\mathrm{CO}_{2}$ malalui pendekatan allometrik. Penelitian ini bertujuan membuat persamaan allometrik untuk menentukan potensi biomassa, potensi karbon, dan potensi penyerapan $\mathrm{CO}_{2}$ di PT. SBK.

\section{DAFTAR PUSTAKA}

Brown, S., 1997. Estimating Biomass and Biomass Change of Tropical Forests: a Primer. (FAO Forestry Paper - 134). FAO, Rome. Clark, William C. (Ed.). 1982. Carbon Dioxide Review, 1982. Oxford University press, New York.

Browning, B.L. 1967. Methods of Wood Cemistrry vol.1. Intercience Publishers, A Division of john Wiley and Sons, Inc. New York.

Brown, S. dan Lugo, and Chapman, J. 1986. Biomassa of topical tree Plantations and its Implications for the Global Carbon Budget. Can. J. for. Res., 16: 390-394

Cannel, M.G.R. 1982. World Forest Biomass and Primary Production Data. Academic Press. A Subsidary of Harcourt Brace Javanivic Publishers. London. New york. Paris. San Diego. 391 pp.

Clark III, A. 1979. Suggested Procedures for Measuring Tree Biomass and Reporting Free Prediction Equations. Proc. For. Inventory Workshop, SAF-IUFRO. Ft. Collins, Colorado: 615-628

Daniel, T.W., J.A Helms., dan F.S. Baker. 1980. Prinples of Silviculture. Mc. Graw Hill Inc. New York.

Hairiah, K. dan Rahayu, S. 2007. Pengukuran Karbon Tersimpan di Berbagai Macam Penggunaan Lahan. Word Agroforestry Centre - ICRAF, SEA Regional Office. University of Brawijaya, Indonesia. $77 \mathrm{p}$.

Supranto, J. 2009. Statistik Teori dan Aplikasi. Edisi ke tujuh.Penerbit Erlangga. Jakarta

Sutaryo, D., 2009. Perhitungan Biomassa: Sebuah Pengantar untuk Studi Karbon dan Perdagangan Karbon. Wetlands International Indonesia Programme. Bogor. 